\title{
PRÉ-TRATAMENTO SOB PRESSÃO ATMOSFÉRICA VISANDO AO AUMENTO DA DIGESTIBILIDADE ENZIMÁTICA DE BAGAÇO DE CANA-DE-AÇÚCAR USANDO GLICEROL EM MEIO ÁCIDO
}

\author{
M. P. SWERTS; P. J. ESTEVES, W. CARVALHO; S. S. SILVA; J. C. dos SANTOS* \\ Universidade de São Paulo - Escola de Engenharia de Lorena, Departamento de \\ Biotecnologia \\ *E-mail para contato: jsant200@usp.br
}

\begin{abstract}
RESUMO - O pré-tratamento da biomassa vegetal visando-se ao aumento de sua digestibilidade enzimática está entre os temas de pesquisa de maior interesse mundial. Para este fim, o uso de condições amenas de processo pode resultar em redução em seu custo global. Neste trabalho, avaliou-se o uso do glicerol em meio ácido para o pré-tratamento do bagaço de cana-de-açúcar sob pressão atmosférica. Experimentos foram realizados em diferentes temperaturas empregando-se meio reacional contendo $5 \% \mathrm{~m} / \mathrm{v}$ de bagaço e $0,5 \% \mathrm{~m} / \mathrm{v}$ de $\mathrm{H}_{2} \mathrm{SO}_{4}$, além de solução de glicerol $95 \%$, sendo também realizados testes em autoclave e meio isento de glicerol. $\mathrm{O}$ material pré-tratado foi submetido à hidrólise enzimática empregando preparado comercial de celulase, a $50{ }^{\circ} \mathrm{C}$ por $24 \mathrm{~h}$. Os resultados obtidos demonstraram que a hidrólise da celulose variou de $11 \%$ (material não tratado) até $41,7 \%$, valor observado com o material pré-tratado a $121{ }^{\circ} \mathrm{C}$ em meio contendo glicerol. Em todos os casos, observou-se que o pré-tratamento resultou em valores médios de hidrólise enzimática superiores aos obtidos com o material não tratado. Esta superioridade foi mais notória a $121^{\circ} \mathrm{C}$, em especial quando glicerol foi empregado no meio. Nesta temperatura, o uso de glicerol resultou em um percentual de celulose hidrolisada de cerca de $40 \%$ em comparação a $27 \%$ de hidrólise empregando-se meio isento deste composto.
\end{abstract}

\section{INTRODUÇÃO}

Os materiais lignocelulósicos constituem-se em fontes abundantes de compostos orgânicos, apresentando grande potencial de uso como matéria prima em processos industriais não apenas como fonte de energia e combustíveis, mas também de alimentos, insumos químicos, enzimas e bens de consumo diversos (Cherubini, 2010). Especificamente com relação à produção de combustíveis, a fração carboidrato destes materiais tem sido empregada na produção de etanol, um importante substituto para a gasolina em veículos de transporte (Sarkar et al., 2012).

A biomassa lignocelulósica é composta majoritariamente por celulose, hemicelulose e lignina, além de outros componentes em menor quantidade. As frações de celulose e hemicelulose são polímeros de carboidratos e uma fonte potencial de açúcares fermentáveis (Medina, 2013). 
Uma das limitações para o aproveitamento integral de todas as frações dos resíduos lignocelulósicos, no entanto, é a própria estrutura da biomassa. Geralmente, é necessária a ruptura do complexo lignina-celulose-hemicelulose ou a remoção de cada fração por técnicas de pré-tratamento e deslignificação. Sem este tratamento preliminar a biomassa é difícil de ser aproveitada em processos industriais, pois a associação de suas frações constituintes lhe confere grande resistência ao ataque de agentes químicos, enzimáticos ou microbianos (Agbor et al., 2011). Diversas opções de pré-tratamento têm sido estudadas, incluindo métodos físicos, químicos, físico-químicos e biológicos (Alvira et al., 2010; Agbor et al., 2011; Modenbach e Nokes, 2012).

Um método de pré-tratamento promissor é o chamado organossolve, o qual pode ser conduzido empregando-se uma variedade de solventes orgânicos em mistura com água, com ou sem a adição de um catalisador como ácidos clorídrico ou sulfúrico. Entre as vantagens das técnicas organossolve, a presença de solventes pode facilitar a penetração dos reagentes na biomassa, aumentando a eficiência na remoção da lignina e a redução na redeposição desta sobre os outros componentes após o processo (Oliet et al., 2001).

O glicerol é um solvente orgânico cuja disponibilidade tem aumentado nos últimos anos, devido ao aumento na produção de biodiesel e sua consequente geração como subproduto. Assim, sua produção mundial tem sido crescente e tem superado a demanda (Sun e Chen, 2008; Zhang et al., 2013a). Neste contexto, no presente trabalho, avaliou-se o uso do glicerol em meio ácido para o pré-tratamento do bagaço de cana-de-açúcar sob pressão atmosférica. Ácido sulfúrico foi empregado no meio reacional, tendo sido realizadas reações em meio isento deste solvente para a geração de dados de comparação.

\section{MATERIAIS E MÉTODOS}

\subsection{Preparo da Matéria Prima}

O material foi seco ao sol até que atingisse um teor de umidade de cerca de $10 \%$ para evitar contaminação microbiana durante a estocagem no laboratório. . Após a secagem, o bagaço foi moído em um moinho de martelo marca Benedetti, modelo dupla 270 (Moinho Benedetti Ltda., Pinhal - SP), até que pelo menos $90 \%$ das partículas passassem por uma peneira padrão Tyler $10 \mathrm{MESH}$ (abertura $1,65 \mathrm{~mm}$ ). O material foi então caracterizado com relação a sua composição em extrativos, celulose, hemicelulose, lignina e cinzas, sendo então empregado nos experimentos de pré-tratamento.

\subsection{Pré-tratamento da Biomassa}

Os ensaios foram executados em duas diferentes temperaturas, $90^{\circ}$ e $121^{\circ} \mathrm{C}$, em frascos Erlenmeyer de $250 \mathrm{~mL}$ contendo um total de $100 \mathrm{~g}$ de meio reacional, conforme explicado a seguir: colocou-se a quantidade desejada de bagaço no frasco Erlenmeyer, adicionando-se água ou solução aquosa de glicerol e aquecendo-se a mistura à temperatura desejada através da imersão do frasco em uma cuba com óleo colocada sobre a placa de aquecimento. Quando a temperatura foi atingida, adicionou-se o ácido, agitou-se o meio com um bastão de vidro e aguardou-se o tempo de reação (10 min), durante o qual o meio não foi agitado. Ao final, 
retirou-se o frasco do banho de óleo e resfriou-se o mesmo em banho de gelo. Uma opção testada para os experimentos a temperatura de $121^{\circ} \mathrm{C}$ foi o uso de autoclave. $\mathrm{O}$ meio reacional era composto por $5 \% \mathrm{~m} / \mathrm{v}$ de bagaço e $0,5 \% \mathrm{~m} / \mathrm{v}$ de $\mathrm{H}_{2} \mathrm{SO}_{4}$, adicionados em água ou a uma solução de glicerol $95 \%$. O sólido pré-tratado foi caracterizado quanto a seus componentes (celulose, hemicelulose, lignina) e submetido à etapa de hidrólise enzimática.

\subsection{Hidrólise Enzimática}

A hidrólise do sólido obtido no pré-tratamento foi conduzida em frascos Erlenmeyer de $50 \mathrm{~mL}$ contendo $15 \mathrm{~mL}$ de meio reacional constituído por suspensão aquosa $2 \%$ de bagaço de cana-de-açúcar pré-tratado (massa seca), $50 \mathrm{mM}$ tampão citrato $\mathrm{pH}=4,5,10 \mathrm{FPU}$ enzimas/g de bagaço pré-tratado, empregando-se coquetel enzimático comercial Dyadic ${ }^{\circledR}$ Cellulase $\mathrm{CP}$ CONC (Dyadic International, Inc., Jupiter, Flórida, USA). Os experimentos foram realizados em incubadora de movimento rotatório (Quimis Q816M20, Quimis Aparelhos Científicos, Diadema, SP, Brasil), sob condições de $50^{\circ} \mathrm{C}$ e $150 \mathrm{rpm}$, por 24 horas. A mistura líquida obtida foi caracterizada com relação ao teor de açúcares empregando cromatografia líquida de alta eficiência (CLAE). O rendimento da hidrólise foi definido como a razão entre a massa de celulose transformada em glicose e a massa total desta fração do material.

\subsection{Métodos Analíticos}

Caracterização composicional do bagaço: Tanto o bagaço in natura quanto pré-tratado foram caracterizados quanto a seus componentes (celulose, hemicelulose, lignina e cinzas), seguindo a metodologia padrão do NREL - National Renewable Energy Laboratory (Sluiter et al., 2010). O bagaço in natura foi também caracterizado com realção à quantidade de extrativos, conforme descrito por Masarin et al. (2011).

Concentração de açúcares, ácido acético e etanol: As análises dos teores de açúcares, ácido acético e etanol foram feitas por cromatografia líquida de alta eficiência em cromatógrafo Agilent Technology 1200 series (Agilent, Estados Unidos). As amostras foram previamente filtradas em filtro Sep Pak C18 e injetadas no cromatógrafo, utilizando-se as seguintes condições: coluna BIO-RAD AMINEX HPX-87H (300 X 7,8 mm) mantida à temperatura de $45{ }^{\circ} \mathrm{C}$; volume de injeção de $20 \mu \mathrm{L}$; detector de índice derefração RID 6A; fase móvel ácido sulfúrico $0,01 \mathrm{~N}$ e fluxo de $0,6 \mathrm{~mL} / \mathrm{min}$.

\section{RESULTADOS E DISCUSSÃO}

\subsection{Caracterização do Material in natura e Após o Pré-tratamento}

O bagaço moído foi caracterizado quanto a seus componentes (celulose, hemicelulose, lignina, extrativos e cinzas), sendo que os dados obtidos são apresentados na Tabela 1.

Os valores apresentados na Tabela 1 estão dentro da faixa comumente relatada na literatura para o bagaço de cana-de-açúcar, embora a composição seja variável de acordo com a origem da amostra. Estas diferenças podem ser atribuídas a diversos fatores relacionados às 
características específicas de cada amostra de bagaço, como variedade, idade, condições de cultivo e tempo de estocagem.

Tabela 1 - Caracterização química da matéria prima

\begin{tabular}{|c|c|}
\hline Componente & Fração \\
\hline Celulose (\%) & $41,3 \pm 2,1$ \\
\hline Hemicelulose $(\%)$ & $29,2 \pm 1,3$ \\
\hline Lignina $(\%)$ & $21,7 \pm 0,6$ \\
\hline Extrativos(\%) & $4,5 \pm 0,4$ \\
\hline $\operatorname{Cinzas}(\%)$ & $3,7 \pm 0,2$ \\
\hline Total $(\%)$ & $100,4 \pm 2,6$ \\
\hline
\end{tabular}

Os experimentos de pré-tratamento foram feitos em frascos Erlenmeyer de $250 \mathrm{~mL}$ com $100 \mathrm{~g}$ de meio reacional: $5 \% \mathrm{~m} / \mathrm{v}$ de bagaço e $0,5 \% \mathrm{~m} / \mathrm{v}$ de $\mathrm{H}_{2} \mathrm{SO}_{4}$ diluído em água ou em uma solução de glicerol $95 \%$, sendo utilizadas duas diferentes temperaturas: $90^{\circ} \mathrm{C} \mathrm{e} 121^{\circ} \mathrm{C}$. Os resultados das composições dos bagaços pré-tratados estão representados na Figura 1.

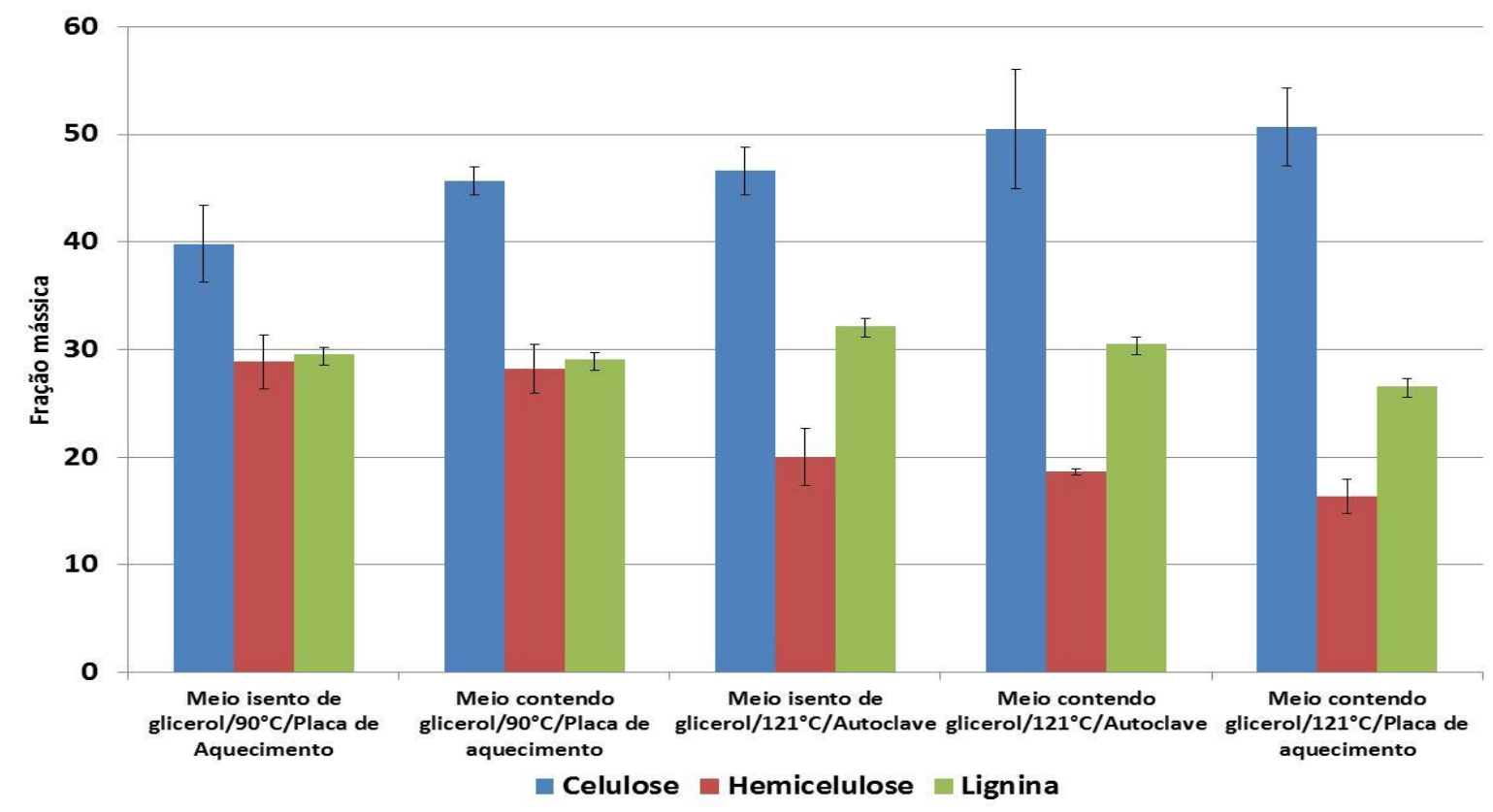

Figura 1 - Composição do bagaço de cana-de-açúcar pré-tratado em deferentes temperaturas, meios reacionais e formas de aquecimento (as barras de erro correspondem ao desvio padrão).

De acordo com os dados obtidos, é possível observar variações nos teores de celulose, hemicelulose e lignina dos bagaços pré-tratados em função do pré-tratamento. Os teores percentuais de celulose variaram de 39,8 a 50,7\% em fração mássica, enquanto a variação no teor de lignina foi de 26,6 a 32,2\%. O componente que mais sofreu variação relativa à composição da matéria-prima (Tabela 1) foi a hemicelulose, variando de 16,3 a 28,8\%. 
De forma geral, houve aumento nos teores de celulose e lignina das amostras prétratadas quando comparados aos da matéria prima, o que está relacionado à remoção da hemicelulose pela ação do ácido sulfúrico diluído (Esteves, 2011). De fato, o pré-tratamento com ácido diluído tem como característica a quebra das cadeias de hemicelulose, resultando na sua despolimerização (Harrison et al., 2013).

Como pode ser observado na Figura 1, os pré-tratamentos a $121^{\circ} \mathrm{C}$ resultaram em maior modificação composicional do bagaço, obtendo-se um percentual de hemicelulose mais baixo e um consequente percentual mais elevado de lignina e celulose quando comparado ao material não tratado (Tabela 1). Este comportamento pode ser explicado, uma vez que, de acordo com Canilha et al. (2011), no pré-tramento com ácido diluído, a temperatura é o fator que mais influencia na solubilização da hemicelulose, seguido pela concentração de ácido e o tempo de residência. Nas reações a $121^{\circ} \mathrm{C}$, pode-se observar também que, quando o glicerol foi usado no meio, o valor médio do percentual de hemicelulose foi reduzido para 16-19\% e, em meio isento deste composto, o valor foi de cerca de $20 \%$. Embora os valores obtidos não apresentem diferenças fora da faixa indicada pelo desvio padrão (Figura 1), essa menor proporção de hemicelulose com o uso do glicerol em meio ácido também foi verificada por Zhang et al. (2013a). A análise da Figura 1 também revela que, usando temperatura de $121^{\circ} \mathrm{C}$, a fração mássica de lignina foi de $32 \%$ no material pré-tratado em meio isento de glicerol comparado a um valor de $27-30 \%$ quando este poliálcool foi utilizado. A solubilidade de lignina pelo glicerol foi classificada como baixa por Zhang et al.(2013b) quando comparada a outros poliálcoois como o etilenoglicol e propilenoglicol. Liu et al. (2010) propôs que a lignina, após um pré-tratamento com glicerol em meio ácido, ficasse retida na matriz dos polissacarídeos.

Com relação à forma de aquecimento empregada, observou-se alguma diferença em especial com relação ao teor de lignina, entre o material pré-tratado em placa de aquecimento e usando autoclave. Estas duas formas de aquecimento foram avaliadas a $121^{\circ} \mathrm{C}$, pois o meio isento de glicerol não poderia ser aquecido sem um sistema pressurizado. Há diferenças, neste caso, em especial com relação ao tempo e eficiência do aquecimento e resfriamento, uma vez que, na autoclave, deve-se aguardar a despressurização do sistema. Não houve, no entanto, diferença significativa com relação à digestibilidade enzimática, conforme será mostrado a seguir.

\subsection{Hidrólise Enzimática}

A etapa de hidrólise enzimática do bagaço pré-tratado foi feita em experimentos com tempo de $24 \mathrm{~h}$, utilizando $10 \mathrm{FPU} / \mathrm{g}$ de preparação comercial de celulase, a $50^{\circ} \mathrm{C}$ e $150 \mathrm{rpm}$. Os valores obtidos estão descritos na Tabela 2 .

Conforme mostrado na tabela, a hidrólise da celulose obtida nos experimentos variou de $11 \%$ (material não tratado) até $41,7 \%$, valor observado com o material pré-tratado a $121^{\circ} \mathrm{C}$ em meio contendo glicerol. Em todos os casos, observou-se que o pré-tratamento resultou em valores médios de hidrólise enzimática superiores aos obtidos com o material não tratado. Esta superioridade foi mais notória a $121^{\circ} \mathrm{C}$, em especial quando glicerol foi empregado no meio, resultando em digestibilidade enzimática cerca de 4 vezes superior à do material não 
tratado. Segundo Esteves (2011), o pré-tratamento com ácido diluído aumenta a digestibilidade enzimática por proporcionar um aumento da área superficial e da porosidade do material.

Tabela 2 - Digestibilidade enzimática do bagaço de cana-de-açúcar não tratado e prétratado em meio contendo ou não glicerol a diferentes temperaturas e com diferentes sistemas de aquecimento

\begin{tabular}{cc}
\hline $\begin{array}{c}\text { Sistema/ } \\
\text { Condições }\end{array}$ & $\begin{array}{c}\text { Rendimento } \\
\text { de Hidrólise (\%) }\end{array}$ \\
\hline Bagaço não tratado & $11,0 \pm 2,4$ \\
Meio isento de glicerol $/ 90^{\circ} \mathrm{C} / \mathrm{Placa}$ de aquecimento & $16,9 \pm 2,0$ \\
Meio contendo glicerol $/ 90^{\circ} \mathrm{C} / \mathrm{Placa}$ de aquecimento & $15,9 \pm 1,8$ \\
Meio isento de glicerol $/ 121^{\circ} \mathrm{C} /$ Autoclave & $26,6 \pm 2,0$ \\
Meio contendo glicerol $/ 121^{\circ} \mathrm{C} /$ Autoclave & $36,6 \pm 5,5$ \\
Meio contendo glicerol $/ 121^{\circ} \mathrm{C} /$ Placa de & $41,7 \pm 5,5$ \\
aquecimento & \\
\hline
\end{tabular}

Os resultados da Tabela 2 foram avaliados empregando teste de Tukey para verificação da significância estatística das diferenças observadas. A Tabela 3 apresenta os resultados desta análise. De acordo com o teste de significância estatística (Tabela 3), os valores de hidrólise da celulose dos materiais pré-tratados a $90^{\circ} \mathrm{C}$ não apresentaram diferença significativa $(p>0,1)$ em relação ao bagaço não tratado. Realmente, o uso de temperaturas mais elevadas tem sido relatado como necessário para aumentar a digestibilidade do material lignocelulósico por celulases. Sun e Chen (2008), empregando pré-tratamento organossolve autocatalítico com solução aquosa de glicerol em palha de trigo, relataram que o rendimento da hidrólise da celulose foi maior em temperaturas mais elevadas.

Tabela 3 - Teste de Tukey para avaliação da significância estatística dos valores de rendimento de hidrólise da celulose do bagaço de cana-de-açúcar não tratado (NT) e prétratado em processo em meio ácido: aquoso a $90^{\circ} \mathrm{C}$ em placa de aquecimento (AP90) ou $121^{\circ} \mathrm{C}$ em autoclave (AA121); contendo $95 \%$ de glicerol a $90^{\circ} \mathrm{C}$ com placa de aquecimento

(GP90) ou a $121^{\circ} \mathrm{C} \mathrm{em}$ placa de aquecimento (GP121) ou autoclave (GA121)

\begin{tabular}{ccccccc}
\hline $\begin{array}{c}\text { Condições } \\
\text { do experimento }\end{array}$ & NT & AP90 & GP90 & AA121 & GA121 & GP121 \\
\hline NT & & 0,3859 & 0,5789 & $0,0022^{*}$ & $0,0002^{*}$ & $0,0002^{*}$ \\
\hline AP90 & 0,3859 & & 0,9990 & $0,0589^{* *}$ & $0,0004^{*}$ & $0,0002^{*}$ \\
\hline GP90 & 0,5789 & 0,9990 & & $0,0322^{*}$ & $0,0003^{*}$ & $0,0002^{*}$ \\
\hline AA121 & $0,0002^{*}$ & $0,0589^{* *}$ & $0,0322^{*}$ & & $0,0474^{*}$ & $0,0027^{*}$ \\
\hline GA121 & $0,0002^{*}$ & $0,0004^{*}$ & $0,0003^{*}$ & $0,0474^{*}$ & & 0,5382 \\
\hline GP121 & $0,0002^{*}$ & $0,0002^{*}$ & $0,0002^{*}$ & $0,0027^{*}$ & 0,5382 & \\
\hline
\end{tabular}

*significativo ao nível de $95 \%$ de confiança; **significativo ao nível de $90 \%$ de confiança 
No presente trabalho, o uso do material pré-tratado a $121^{\circ} \mathrm{C}$ resultou em hidrólise da celulose com superioridade estatisticamente significativa em relação ao obtido com o bagaço não tratado $(\mathrm{p}<0,05)$. Nesta temperatura, o uso de meio ácido isento de glicerol no prétratamento resultou em hidrólise de $27 \%$ da celulose na etapa enzimática comparado a uma hidrólise de $17 \%$ observada no material tratado em meio isento de glicerol a $90^{\circ} \mathrm{C}$. Conforme o teste de Tukey (Tabela 3), a diferença entre estes valores foi estatisticamente significativa ao nível de confiança de $90 \%$.

Essa maior eficiência do pré-tratamento usando o glicerol no meio com relação ao aumento na digestibilidade do material foi relatada também no trabalho de Zhang et al. (2013a). Estes autores, empregando bagaço de cana-de-açúcar pré-tratado durante 60 min com solução aquosa $1,2 \%$ de $\mathrm{HCl}$ à temperatura de $130^{\circ} \mathrm{C}$, obtiveram um rendimento de hidrólise cerca de 3 vezes maior quando o meio possuía glicerol. Segundo Liu et al. (2010), o uso do glicerol no pré-tratamento contribui para o aumento da porosidade do material, facilitando o ataque enzimático à fração celulósica.

\section{CONCLUSÃO}

O presente trabalho teve como objetivo avaliar a influência do emprego de solução aquosa de glicerol no pré-tratamento do bagaço de cana-de-açúcar com ácido sulfúrico diluído e seu efeito na etapa de hidrólise enzimática. Os resultados demonstraram que a temperatura tem um efeito significativo na solubilização da fração hemicelulósica e o uso de $121^{\circ} \mathrm{C}$ resultou em um maior rendimento na etapa de hidrólise enzimática comparado ao uso de $90^{\circ} \mathrm{C}$, empregando-se ou não glicerol no meio. Verificou-se também que o uso do glicerol no meio reacional utilizado para o pré-tratamento do bagaço de cana-de-açúcar proporciona uma maior digestibilidade enzimática em comparação à reação em meio isento de glicerol.

\section{AGRADECIMENTOS}

Os autores agradecem à Fundação de Amparo à Pesquisa do Estado de São Paulo (FAPESP) pelo suporte financeiro.

\section{REFERÊNCIAS}

AGBOR, V. B.; CICEK, N.; SPARLING, R.; BERLIN, A.; LEVIN, D. B. Biomass pretreatment: Fundamentals toward application. Biotechnology Advances, v.29, p.675-685, 2011.

ALVIRA, P.; TOMÁS-PEJÓ, E.; BALLESTEROS, M.; NEGRO, M. J. Pretreatment technologies for an efficient bioethanol production process based on enzymatic hydrolysis: A review. Bioresource Technology, v.101, p.4581-4861, 2010.

CANILHA, L. ; SANTOS, V. T. O.; ROCHA, G. J. M.; SILVA, J. B.; GIULIETTI, M; SILVA, S. S.; FELIPE, M. G. A.; FERRAZ, A. ; MILAGRES, A. M. F.; CARVALHO, W. A study on the pretreatment of a sugarcane bagasse sample with dilute sulfuric acid. Journal of industrial microbiology \& biotechnology, v.38, p.1467-1475, 2011. 
CHERUBINI, F. The biorefinery concept: Using biomass instead of oil for producing energy and chemicals. Energy Conversion and Management, v. 51, p. 1412-1421, 2010.

ESTEVES, P. J.. Pré-tratamento do bagaço de cana-de-açúcar com $\mathrm{H}_{2} \mathrm{SO}_{4}$ diluído em reator piloto aquecido por vapor direto. 2011. 93p. Dissertação (Mestrado em Ciências) Escola de Engenharia de Lorena, Universidade de São Paulo, Lorena, 2011.

GHOSE, T. K; Measurement of cellulase activities. Measurement of Cellulase Activities. Pure \& Appl. Chem. v.59, p.257-268, 1987.

HARRISON, M. D.; ZHANG, Z.; SHAND, K.; O'HARA, I. M.; DOHERTY, W. O. S; DALE, J. L.. Effect of pretreatment on saccharification of sugar cane bagasse by complex and simple enzyme mixtures. Bioresource Technology v.148, p.105-113, 2013.

LIU,J.; TAKADA,R.; KARITA,S.;WATANABE,T.; HONDA,Y.;WATANABE,T..Mic rowave assisted pretreatment of recalcitrant softwood in aqueous glycerol. Bioresource Technology, v.101, p.9355-9360, 2010.

MASARIN, F.; GURPILHARES, D. B.; BAFFA. D. C. F.; BARBOSA, M. H. P.; CARVALHO, W.; FERRAZ, A.; MILAGRES, A. M. F. Biotechnology for Biofuels. 4 : 55, 2011.

MEDINA, K. J. D. . Produção de bioetanol a partir de hidrolisado hemicelulósico de bagaço de cana-de-açúcar empregando as leveduras Scheffersomyces (Pichia) stipitis NRRL Y-7124 e Candida shehatae UFMG HM 52.2 visando à aplicação em bioprocessos com campo eletromagnético. 2013. 172 p. Tese (Doutorado em Ciências) - Escola de Engenharia de Lorena, Universidade de São Paulo, Lorena, 2013.

MODENBACH, A.; NOKES, S. E. The Use of High-Solids Loadings in Biomass Pretreatment-A Review. Biotechnology and Bioengineering, v.109, p.1430 - 1442, 2012.

OLIET, M.; RODRIGUEZ, F.; GARCIA, J.; GILARRANZ, M.A. The effect of autocatalyzed ethanol pulping on lignin characteristics. $J$ Wood Chem Technol, v.21, p.81-95, 2001.

SARKAR, N.; GHOSH, S. K.; BANNERJEE, S.; AIKAT, K. Bioethanol production from agricultural wastes: An overview. Renewable Energy. v. 37, p. 19-27, 2012.

SUN, F.; CHEN, H. Organossolv pretreatment by crude glycerol from oleochemicals industry for enzymatic hydrolysis of wheat straw. Bioresource Technology, v.99, p.54745479, 2008.

ZHANG, Z.; O'HARA, I. M.; DOHERTY, W. O. S; Pretreatment of sugarcane bagasse by acidified aqueous polyol solutions. Cellulose v.20, p.3179-3190, 2013 b.

ZHANG, Z.; WONG, H.; ALBERTSON, P. L.; DOHERTY, O. S.; O'HARA, I. M. Laboratory and pilot scale pretreatment of sugarcane bagasse by acidified aqueous glycerol solutions. Bioresource Technology, v.138, p.14-21, 2013a. 